\title{
Development Professionals: Reconciling Personal Values with Professional Values
}

\author{
Neranjana Gunetilleke, Nilakshi De Silva and Gayathri Lokuge
}

\begin{abstract}
'I do not separate my scientific inquiry from my life. For me, it is really a quest for life, to understand life and to create what I call living knowledge - knowledge which is valid for the people with whom I work and for myself.'

(Marja-Liisa Swantz, quoted in Reason and Bradbury 2007)
\end{abstract}

\begin{abstract}
This article is the result of conversations among a group of development professionals associated with the Centre for Poverty Analysis (CEPA) in Sri Lanka, around questions of the values with which we conduct our work and what this means for our practice. Prompted by the opportunity presented by the Reimagining Development initiative and in the wake of the global financial crisis of 2008 , specifically we asked: Is there tension between values that drive our life and those that drive the 'development' we promote? Is there tension between our personal aspirations and the type of development we promote for the 'poor'? What are the implications on us as individuals and as professionals? What are the implications on the 'targets' of the development that we promote? The discussion that follows is based on a structured process of reflection and discussion of ideas among a purposively selected group of professionals, all institutionally linked to CEPA. The analysis of how these values are reconciled provides a useful basis to take the discussion of an alternative, value-driven development paradigm forward.
\end{abstract}

\section{Introduction}

During the past three years, the world has been beset by multiple crises. The food and fuel price increases, followed by the global financial crisis have shaken our collective faith in global economic and financial systems and led to numerous attempts to rethink the way forward. The socioeconomic and political reflections that followed the outbreak of these crises have tended to agree that they are driven, or at least are facilitated, by a world view that condones greed and excessive consumption (Blinder 2010). Nevertheless, many development analysts continue to uphold these values, arguing that greed is simply the compulsion that helps anthropomorphise the capitalistic spirit; that there is nothing intrinsically wrong with greed; or even that greed is good because it drives competition and innovation (Willett 2009).
The dominant development paradigm over the past decades has been based on some version of capitalism, with a strong focus on improving material wellbeing and accumulation. In reality however, 'development' is not confined to economic growth and a direct association of wellbeing with consumption. The focus on and encouragement of material wellbeing can work in direct opposition to the personal values and aspirations which many people derive from their spiritual beliefs, such as moderation, nonaccumulation, self-control, generosity and sharing. Among development professionals, tensions can develop between the values they aspire to in their personal space, and those that they promote in their professional space. These tensions can be aggravated when the poor people that they work with also relate to the values of personal rather than professional space. 

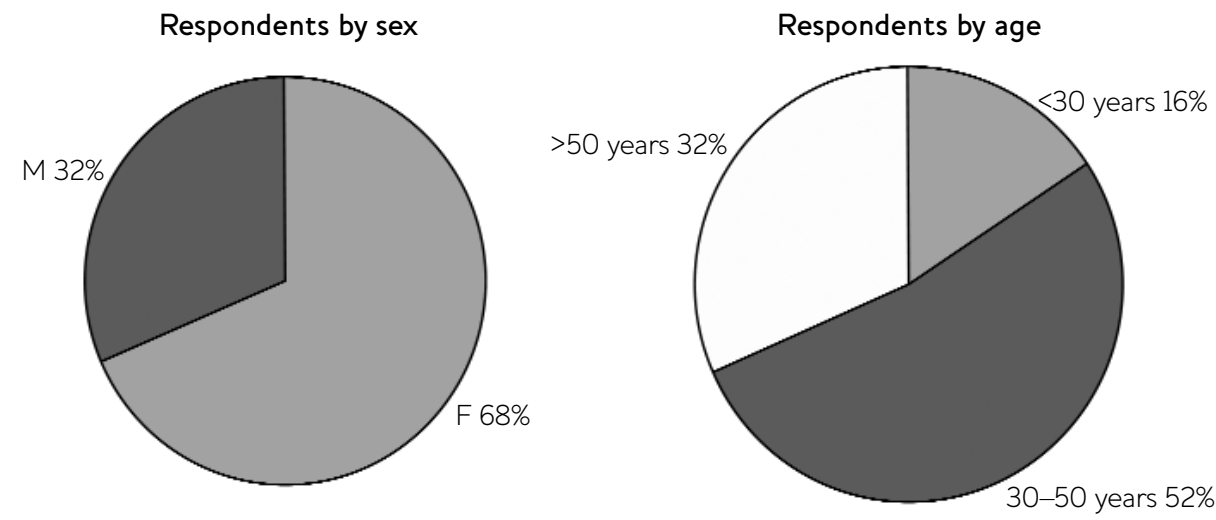

Respondents by educational qualification

Respondents by discipline
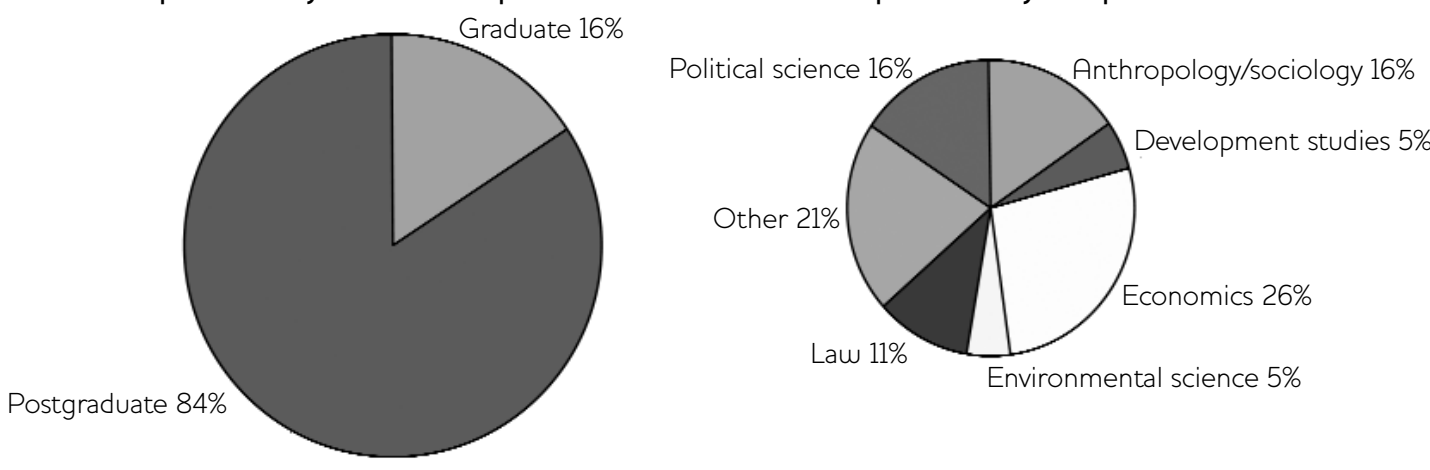

The recent crises - and the financial crisis in particular - exposed the problems that arise in promoting a consumption-based vision of development on a global scale and they highlight some of the internal contradictions inherent in materialistic development trajectories. For example, current development paradigms appear to promote a tendency towards rewarding extreme individualism at the expense of the common good; immediate gratification at the expense of the long term; and over-consumption and waste over moderation. Many people working on development issues have long been uncomfortable with some of the values promoted in these development visions, which are too often taken for granted. While the crises may not have triggered a shift in ideas and values per se, they have created a more encouraging space for alternative ideas and values to be entertained in international development discourse. The aim of this research site was to explore whether the personal values and

aspirations of development professionals can provide a starting point to amend and improve mainstream development thinking.

\section{Methodology}

This research methodology was a structured process of reflection and discussion of ideas among a purposively selected group of persons.

The respondents were all Sri Lankan development professionals and the majority lived and worked in Sri Lanka. Most of these were research-oriented professionals rather than development practitioners. The Centre for Poverty Analysis (CEPA) is the focus of the 'virtual' community, which is the basis of the study, and all the respondents were either staff, board members or subscribing members. However, beyond this within this institutional group, no selection was made on any further basis. All persons were invited to participate in the study. 
The discussion questions were posted up on the CEPA staff blog and also circulated via e-mail to the board of directors and subscribing members. Out of a total of 40 development professionals who had access to the questions, 19 written responses were received. Respondents were mainly female, aged 30-50, who had postgraduate degrees and a range of social science backgrounds (see Figure 1 for a respondent profile). They were from various professional backgrounds, such as government, international organisations, the private sector and the not-for-profit sector, and a number had experience across multiple sectors. About half of the respondents were Buddhist, the remainder being Christian, Muslim or agnostic.

The research questions driving the study were:

- Is there a disjunct between professional and personal values of development professionals regarding the vision of 'development'?

If Yes,

- Where does the disjunct come from?

- What are the implications of this disjunct?

To explore these, further discussion questions were formulated in order to draw out any tensions experienced by development professionals regarding the values inherent in global development thinking and their personal values and aspirations. The questions were:

1 What do you think are the main values that drive global development?

2 Is there a difference between the values inherent in the global development discourse and your personal values regarding your vision for your own development?

3 What is the source of these two types of values for you? Particularly, what is the source of your personal values?

4 Do you think there are any implications of the above ideas, for your work? For the solutions/ development you promote in your work?

The responses were analysed first to understand: the general perceptions on the values that drive global development: the perception of a presence or absence of a disjunct between personal and professional values; and the implications of this disjunct for the work of development professionals. Following the initial analysis, a roundtable discussion with the respondents sought to bring together the different ideas into one forum. Further analysis and synthesis of the points discussed resulted in this think piece.

\section{Key ideas and themes}

\subsection{The development paradigm}

Development professionals typically work in a space dominated by a discourse that equates 'development' with 'economic development', and even more narrowly to development based on accumulation, and increasing production and consumption. Critiques of this discourse have emerged from within and outside the economic space, some from within the market-oriented mainstream itself. These include: Marxist critiques; Sen's capabilities and functionalities approach to development; the environmentalist approaches of sustainable development and commons discourse; feminist-critiques of the 'structures of dominance'; rights-based approaches including the Millennium Development Goals (MDGs). All of these have impacted mainstream development conversations and are succeeding in broadening the scope of what development is expected to achieve. Other paradigms which are founded explicitly on value-based approaches, such as Schumacher's philosophy of 'enoughness' and Thailand's 'sufficiency economy', are widely known but are not yet a part of the mainstream global discourse.

The development professionals participating in this research recognised the existence of a dominant discourse in development thinking and variously characterised it as 'economistic', 'capitalism', 'the search for profit', 'economic growth', 'accumulation', 'focus on consumption and materialism', 'individualism', 'competition and consumerism' or 'the drive to achieve/attain more'. This characterisation is accompanied by frequently expressed and sometimes implied uneasiness with its inherent values:

Capitalism dominates global development. Profit motive, commoditisation of social life drives capitalism. While it can overcome absolute poverty, inequality is a hallmark of capitalism. (Respondent 04) 


\section{Box 1 Sources of personal values}

Values: the social principles, goals, or standards held or accepted by an individual, class, society, etc. (Webster's New World College Dictionary)

Values are seated in the mind; below [the] pure thinking of the philosopher and mathematician, but above the mechanical thought processing that turns facts into understanding. (Anonymous; quoted on Growth Online: Knowledge Base and Encyclopaedia of Life and Human Consciousness)

Personal values can be of many types, some of which overlap, for example ethical and moral values relate to the distinction between right or wrong conduct; religious and spiritual values relate to beliefs about human existence.

For the respondents, personal values appear to be derived from a mix of their family background, religious beliefs and the circumstances they have faced in their lives. For some, family and religion is linked together, while for others, the religious influence is a conscious decision where the values and philosophy of a given religion is seen as a strong source of personal values. The exposure to other cultures and other ways of thinking through travel and the opportunity to compare those value systems with their own have also moulded the personal values of the respondents.

... it still seems true that money and its associated evils drive mainstream development. The general idea of a developed city for example... seems to be one with lots of tall buildings, shiny cars and a few ornamental, strategically placed trees. (Respondent 15)

While accepting the centrality of a basic level of material wellbeing being met for everyone, there was uneasiness that there is no upper limit to material wellbeing either prescribed or even considered. This is perceived as allowing those who have the ability and willingness to consume to do so at the expense of those who lack, as well as at the expense of the planet as a whole. Importantly, a distinction was made between the impact on society/the planet and the impact on individuals. It was proposed by some that the dominant development values ignored or eroded the potential for personal contentment and spiritual growth.

The main clash comes in being entrapped in never-ending competition for achievement measured by material gains, possessions/assets, position and influence - with little scope for contentment... My own view of development is to have access to opportunity equitably but to be contented. Development without emphasis on contentment is destructive.

(Respondent 07)
There was also a strong acknowledgment of the diversity in development discourses and values driving development. For example, development as human development; as promoting equity; safeguarding rights; as empowerment; and emphasising environmental sustainability, are all also seen as elements of the development discourse.

I believe that at present three categories of values drive global development: One based on 'charitable concepts' such as poverty reduction, better health and basic education for the poor typified by MDGs; the second, helping developing countries to adopt development management/governance that is considered 'good' by the donors are based on individualism, competition and consumerism and their safeguard; and the third based on the emerging acceptance that development is an endogenous process based on the values and priorities of the beneficiaries.

(Respondent 07)

\subsection{Personal values}

For many of the development professionals involved in this discussion, personal values were quite different and unrelated to professional values. These personal values included ideas such as tolerance of others' beliefs, sharing, time and care for others, honesty, integrity, decency in doing business, exposure to and understanding of 
other cultures, countries and religions. In some cases, these involved values that were

diametrically opposite to the dominant paradigm; such as less waste, more focus on responsibilities than rights, less focus on material excess, contact and influence of spirituality/religion and so on.

Yes there is a difference [between the values inherent in the global development discourse and my personal values]. Coming from the South I think we are raised to think about others as well (individuals vs your family, your extended family, others in your community and country who may not be as privileged as you). (Respondent 08)

I strongly believe in values such as selfdiscipline, integrity, respect for one another, and equality as factors contributing to my own development, but I cannot see how these values I believe in can contribute to the global development. (Respondent 09)

These differences may be arising due to the different sources from which these values are derived (Box 1).

\subsection{Tension between the professional and the personal}

Development professionals deal with the perceived tension between their professional and personal values, either by working them out, or choosing to work in areas where there is little tension with their personal values. In this sample, there were also some who have not worked out the tensions at all.

Those who see a disjunct but have worked out the tensions have done so in different ways. One respondent uses personal values stemming from her religious philosophy to understand and come to terms with occurrences in the global political economy, which is her professional space.

For me, there is no clash between the values inherent in the global development discourse and my personal values regarding my vision for my own development. Since I look at the phenomena of development and economic change through the perspective of the Dhamma, I feel that I can understand, and accept, many things that have happened, and are happening, and also be happy about what has been achieved against all odds.

(Respondent 06)
A different perspective is offered by another respondent, who resolves the disjunct by placing the personal values above the values of the dominant discourse.

I am guided by my personal convictions and not by the agendas of global, regional or local development or political actors. But in terms of profit, this attitude does not financially help me. But that is not the end of the world. (Respondent 03)

The more commonly held perception was that there is no unresolvable disjunct between personal and professional values because the global discourse is so diverse. Differing values are seen as driving different approaches to development. Given this diversity, respondents feel they are able to choose the professional values they subscribe to.

I agree with some of the approaches [and] values evident in the global development discourse, which is not homogenous, particularly the notion of the Right to Development. (Respondent 02)

Personally, I do not subscribe to material accumulation... However, I do subscribe to the political values of development - the values of democracy, equity and rights of individuals, particularly the rights of lower caste groups... and of women. (Respondent 11)

These responses emphasise that personal values tend to drive the challenge against dominant discourses. Rather than merely observe or accept the world we live in, these respondents seek to change it in line with their personal beliefs.

The challenge is to build on the theories and knowledge that the alternate discourse of development (to the conventional neoliberal, economistic discourse) brings to development. To think that there is just one discourse is a bit too narrow. It also brings the 'need to influence' very much into the core of what I want to do - because I want to challenge the dominant discourse. I think reimagining development has been the total focus of my professional life. (Respondent 11)

Among the professionals participating, none found their personal values agreeing with the dominant 
economic values of unlimited production and consumption, continuously increasing material wealth and the focus on profit, economic efficiency, etc. The respondents either choose to work within a sub-group which agrees with their personal values, or they seek to challenge the dominant discourse; at worst, they learn to 'live with it'.

\subsection{Implications}

The research implies an often unacknowledged but felt disjuncture between the values that dominate the main development paradigm and personal values of development professionals. Many deal with this by separating professional and personal lives to conform to expectations, in common with other professionals, and particularly those engaged in research. Bringing personal values, which are often culturally rooted, into one's work is regarded by many as 'unscientific' and unprofessional.

The reluctance of some respondents to articulate and publicly discuss their values stems from the perceived need to maintain their 'professionalism' and show an ability to separate the two sets of values and specifically perform one's work without being influenced by personal values. Despite the sample group's orientation towards enquiry, analysis and writing, there was a marked lack of spontaneous, written responses. Some felt the need to discuss the questions, their responses and feelings prior to providing written inputs. These issues highlight the rigidity with which personal space is separated from the professional.

This, however, is an artificial separation, which assumes the ability of a person to have (or forces them to have) dual values. Its roots lie in the modern conception of 'science', which is linked to the development of secularism; such that values in one's scientific role are 'professional', rather than human. In pre-modern society, the separation between professional and personal values was not as marked, since the same belief systems set the standard for both professional and individual behaviour. 'Scientific' professions ranging from physical healing to civil engineering were linked to spirituality, personal 'goodness', moral values, ethics and social benefit. However, with the secularisation of education and knowledge and with the development of modern Western scientific thought, a distinction came to be established and concepts of 'science' and 'professionalism' assumed a level of abstraction and universality that detaches it from personal moral values.

The predominance of liberal economic thought within development discourse, and more importantly, in the practice of development, can be identified as a key factor that currently generates tensions in respect of values. The analysis of the human condition is very similar among economics, psychology and spiritual philosophy. Key thinkers in these various fields, such as Adam Smith, Victor Frankl (1971) and Gautama Buddha all agree that humans are prone to unlimited desires and seek means of fulfilling them. However, their proposed solutions for humanity contrast starkly. Both Gautama Buddha and Victor Frankl acknowledge that the fulfilment of human desires is an impossible and undesirable end. This suggests a path of mental development to control and overcome these desires. Adam Smith on the other hand, develops a theory on how best these human desires may be served, thus securing the foundation for a system of values that drives the current understanding of development - development driven by economic achievement, either individual or collective (Tilakaratne 2008).

\section{Conclusion}

The question then is: What needs to change? In development thinking and practice should we live with the duality and tension between professional and personal values? Or should we try to bring the professional in line with the personal? This research raises many more questions than it can actually answer.

But, while they acknowledge the challenge, respondents felt that at this time, there is space for change in the development discourse.

... And the very fact that we have a global development discourse - that is also a result of the worldwide consensus which has developed that poverty is unwholesome, that something needs to be done to alleviate it... and that the better-off are duty-bound to help the worse-off. There is also a worldwide consensus that people need to be educated, that they need to develop their skills. So as the world contracts through greater connectivity, facilitated by the technological revolution, we can also see a universalisation of some wholesome values. (Respondent 06) 
Some potential 'wholesome values' identified by a number of respondents include introducing ideas of contentment, limits to consumption and development discourse that focuses not just on the poor but also on over-consuming segments of the population. Another set of ideas promote introducing the concept of 'enlightened' selfinterest into the economistic discourse, in that with access to education, individual choices will not only reflect the drive to maximise individual consumption and satisfaction but that of the community as well.

As the Reimagining Development initiative notes, the global crises have exposed the weaknesses of neoliberal, profit and consumption-oriented ideologies which have

\section{References}

Blinder, A.S. (2010) 'When Greed is not Good', Online Wall Street Journal, online.wsj.com (accessed 21 May 2010)

Frankl, V. (1971) Man's Search for Meaning, Boston MA: Beacon Press

Growth Online (undated) Knowledge Base and Encyclopaedia of Life and Human Consciousness, www.gurusoftware.com (accessed 20 May 2010)

Reason, P. and Bradbury, H. (2007) 'Inquiry and Participation in Search of a World Worthy of dominated development thinking in the recent past. At the same time, in our personal space, many of us aspire to a world in which selfinterest, greed and limitless growth are not the driving values. It is not too difficult to understand the existence of tensions for professionals working within these contrasting world views. However, these tensions need to be constructively resolved because, very often development professionals set the course for life improvement for those they work with or for. The main conclusion, therefore, is that there should be ongoing conversations about the 'end' or vision of development, and an attempt to attribute the same kind of legitimacy to valuedriven development, as is now accorded to economistic development.

Human Aspiration', in P. Reason and H. Bradbury (eds), Handbook of Action Research, London: Sage Publications

Tilakaratne, A. (2008) Buddhist Economic Philosophy in Human Problems in a Buddhist Perspective, Colombo: Kurulu Publications

Willett, B. (2009) 'Financial Crisis: Blaming the Culture of Greed', 7 April, The Market Oracle, www.marketoracle.com (accessed 17 May 2010) 